\title{
1 Synthesis of amide-functionalized cellulose esters by olefin cross-metathesis
}

2 Xiangtao Meng ${ }^{\mathrm{a}, \mathrm{b}}$ and Kevin J. Edgar ${ }^{\mathrm{a}, \mathrm{b}^{*}}$

$3{ }^{a}$ Macromolecules and Interfaces Institute, Virginia Tech, Blacksburg, VA 24061, United States

$4 \quad{ }^{b}$ Department of Sustainable Biomaterials, Virginia Tech, Blacksburg, VA 24061, United States

5 * Corresponding author: E-mail: kjedgar@vt.edu; Tel: +1-540-231-0674.

\section{Abstract}

Cellulose esters with amide functionalities were synthesized by cross-metathesis (CM)

8 reaction of terminally olefinic esters with different acrylamides, catalyzed by Hoveyda-Grubbs

$92^{\text {nd }}$ generation catalyst. Chelation by amides of the catalyst ruthenium center caused low

10 conversions using conventional solvents. The effects of both solvent and structure of acrylamide

11 on reaction conversion were investigated. While the inherent tendency of acrylamides to chelate

$12 \mathrm{Ru}$ is governed by the acrylamide $\mathrm{N}$-substituents, employing acetic acid as a solvent significantly

13 improved the conversion of certain acrylamides, from $50 \%$ to up to $99 \%$. Homogeneous

14 hydrogenation using $p$-toluenesulfonyl hydrazide successfully eliminated the $\alpha, \beta$-unsaturation

15 of the $\mathrm{CM}$ products to give stable amide-functionalized cellulose esters. The amide-

16 functionalized product showed higher $\mathrm{T}_{\mathrm{g}}$ than its starting terminally olefinic counterpart, which

17 may have resulted from strong hydrogen bonding interactions of the amide functional groups. 


\section{Introduction}

Amide functionality on the backbone or side chain of a polymer can not only affect physical, chemical, and mechanical properties (Kaczmarczyk \& Danuta, 1995), but also polymer-polymer (Lin, Zhang, Dong, Dong \& Li, 2007) or polymer-small molecule (Yu \& Mosbach, 1997) interaction by secondary forces like hydrogen bonding (Gellman, Dado, Liang \& Adams, 1991; Hagler, Huler \& Lifson, 1974; Lifson, Hagler \& Dauber, 1979). Although amide-containing synthetic polymers (e.g. nylons) as well as some natural polymers such as proteins have been well studied, to date relatively few studies have focused on the synthesis and properties of amide functionalized cellulose and other polysaccharide derivatives. This is in part because of the limited number of synthetic approaches that have been described to prepare such derivatives. Amidation of carboxylic acid containing polysaccharides or their derivatives (e.g. carboxymethyl cellulose) with amines gives substituted amides; this method can be challenging since polysaccharide hydroxyl groups may also be reactive towards an activated carboxyl group (Benkaddour, Journoux-Lapp, Jradi, Robert \& Daneault, 2014; Zabivalova, Bochek, Kalyuzhnaya, Vlasova \& Volchek, 2003). In a reversal of reactivity, amidation between aminocontaining polysaccharides (e.g. chitosan) with carboxylic acids or acid chlorides has also been employed; the required amino substituted polysaccharide may not be readily available, and issues of N/O selectivity can also surface with this method (Ruiz Matute, Cardelle-Cobas, García-Bermejo, Montilla, Olano \& Corzo, 2013).

Olefin metathesis has been proven to be a powerful tool for synthesis of a variety of both small and polymeric molecules by scission and regeneration of carbon-carbon double bonds (Grubbs, 2004). Successful synthesis of small molecule amides through cross-metathesis (CM) has also been reported (Barrett et al., 2004; Choi, Chatterjee \& Grubbs, 2001; Formentin, Gimeno, Steinke \& Vilar, 2005; Streuff \& Muñiz, 2005). In 2001, the Grubbs group investigated the synthesis of $\alpha, \beta$-unsaturated amides by cross-coupling reaction of simple terminal olefins with corresponding amides (e.g. acrylamide) (Choi, Chatterjee \& Grubbs, 2001). Olefin CM chemistry has been adopted by the Edgar (Meng, Matson \& Edgar, 2014a, b) and other groups (Joly, Granet \& Krausz, 2005; Malzahn, Marsico, Koynov, Landfester, Weiss \& Wurm, 2014) for polysaccharide modification towards discrete or cross-linked products. In our previous studies, cellulose esters with side-chain functionalities of carboxylic acid and a variety of 
51 carboxylate esters were synthesized by CM between $\omega$-unsaturated cellulose esters (e.g. cellulose

52 acetate undec-10-enoate) and CM partners including acrylic acid and the corresponding acrylates

53 (Figure 1). This synthetic pathway has been demonstrated to be a modular and efficient route to

54 families of novel polysaccharide derivatives, providing a valuable platform for structure-property

55 relationship studies.
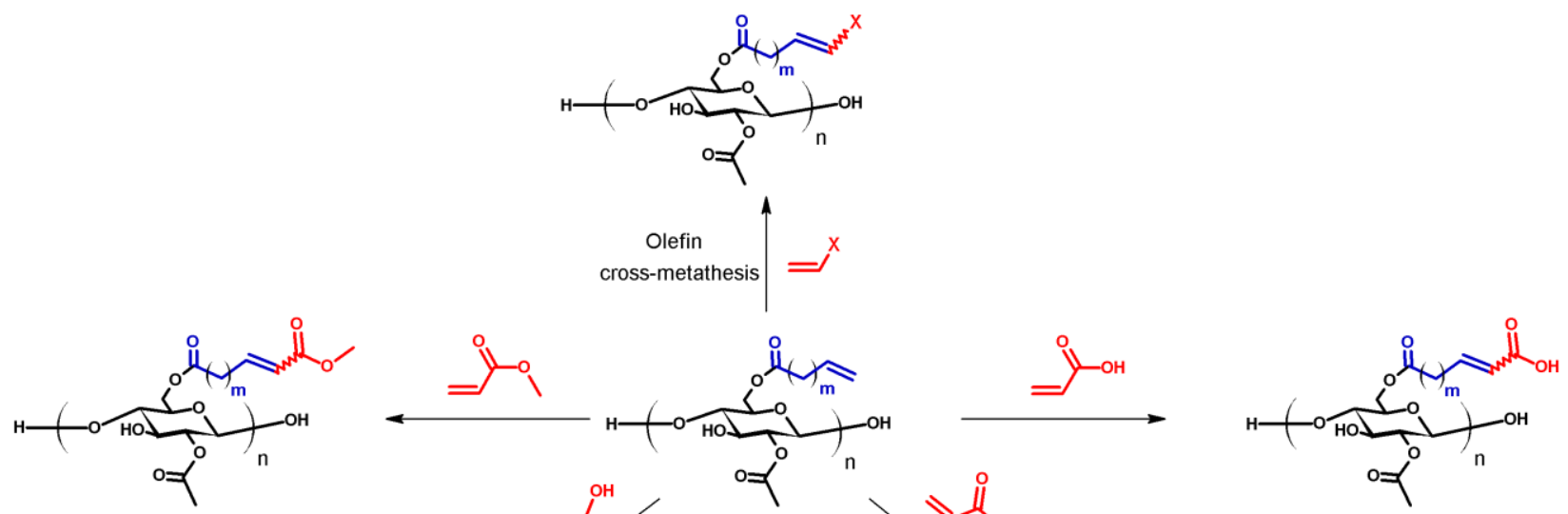

57 Figure 1. General scheme of olefin CM between terminally olefinic cellulose ester and different 58 CM partners.

However, to the best our knowledge, there have been no reports of synthesis of $\alpha$, $\beta$ unsaturated amides using olefin $\mathrm{CM}$ to achieve either synthetic polymer or polysaccharide

61 modification. This may be due to the fact that amides tend to chelate with the olefin metathesis 62 catalyst, and thus the reaction could be expected to afford even lower conversion in a polymer 63 system than the incomplete conversions previously observed for small molecules (Choi, 64 Chatterjee \& Grubbs, 2001). We hypothesize that it may be possible to carry out olefin CM 65 reactions between terminally unsaturated cellulose esters and acrylamides, so long as the proper 66 solvents or additives are used to minimize deactivation of the metathesis catalyst by the amide 67 groups. Herein, we report our approaches to synthesis of amide-functionalized cellulose esters by cross-metathesis reaction between terminally olefinic cellulose esters and acrylamides. We also 
69 describe the impact of using organic acids (i.e. acetic acid) as solvents for CM reactions with 70 acrylamides, and try to rationalize the observed effects via a preliminary structure-activity 71 relationship study. Furthermore, we propose a hydrogenation protocol to eliminate instability 72 caused by labile $\gamma$-hydrogens in the initial $\alpha, \beta$-unsaturated CM products. As mentioned earlier, 73 intra- and intermolecular hydrogen bonding interaction via amide functionality may invest 74 polymers with properties of interest for applications such as amorphous solid dispersion 75 formulation (Taylor \& Zografi, 1997) and molecular recognition (Yu \& Mosbach, 1997). The 76 current study focuses on our attempts to prove the concept of our hypothesis by developing a 77 synthetic approach towards amide-functionalized cellulose derivatives, which may have great 78 promise for these and other applications.

79 


\section{Experimental Section}

\section{Materials}

Cellulose acetate (CA-320S, $M_{n} 38.0$ kDa, DS(Ac) 1.82) was from Eastman Chemical Company. The molecular weight information was reported by the supplier and the DS value was previously measured by our group (Kar, Liu \& Edgar, 2011). Triethylamine (TEA) and 1,3-dimethyl-2imidazolidinone (DMI) were purchased from Acros Organics. Dimethyl formamide (DMF), glacial acetic acid, ethyl acetate (EtOAc), methyl ethyl ketone (butanone, MEK) and ethyl ether were purchased from Fisher Scientific. Undec-10-enoyl chloride, Hoveyda-Grubbs $2^{\text {nd }}$ generation catalyst, $p$-toluenesulfonyl hydrazide, acrylamide, $N$-phenylacrylamide, $N, N$ dimethylacrylamide, tetrahydrofuran (THF), butylated hydroxytoluene (BHT) and $N$ isopropylacrylamide were purchased from Sigma-Aldrich. DMI and DMF were dried over $4 \AA$ molecular sieves before use. All other purchased reagents were used as received.

\section{Measurements}

${ }^{1} \mathrm{H}$ NMR spectra were acquired on a Bruker Avance 500 spectrometer operating at $500 \mathrm{MHz}$ with 16 scans. Samples were analyzed as solutions in $\mathrm{CDCl}_{3}$ or $\mathrm{DMSO}_{6}(\mathrm{~d}$. $10 \mathrm{mg} / \mathrm{mL})$ at $25{ }^{\circ} \mathrm{C}$ in standard $5 \mathrm{~mm}$ o.d. tubes. Three drops of trifluoroacetic acid were added to shift the water peak downfield from the spectral region of interest. ${ }^{13} \mathrm{C}$ NMR spectra were obtained on a Bruker Avance 500 spectrometer with a minimum of 5000 scans in DMSO-d 6 (ca. $50 \mathrm{mg} / \mathrm{mL}$ ) at $25{ }^{\circ} \mathrm{C}$. To obtain the $\mathrm{T}_{\mathrm{g}}$ values of the cellulosic polymers, DSC was performed on a TA Instruments Q2000 apparatus using a heat/cool/heat cycle. Dry powders (ca. $5 \mathrm{mg}$ ) were loaded in TA hermetic aluminum pans. Each sample was equilibrated at $-50{ }^{\circ} \mathrm{C}$ before heating to $160{ }^{\circ} \mathrm{C}$ at the rate of $20^{\circ} \mathrm{C} / \mathrm{min}$, followed by quenching to $-50{ }^{\circ} \mathrm{C}$ and heating to around $200{ }^{\circ} \mathrm{C}$ at a rate of $20^{\circ} \mathrm{C} / \mathrm{min}$. FTIR spectra were obtained on a Nicolet 8700 instrument. Size exclusion chromatography (SEC), if not otherwise specified, was performed on an Agilent 1260 Infinity Multi-Detector SEC using DMAc with $0.1 \mathrm{M} \mathrm{LiCl}$ as the mobile phase $\left(50^{\circ} \mathrm{C}\right)$ with 3 PLgel $10 \mu \mathrm{m}$ mixed-B $300 \times 7.5 \mathrm{~mm}$ columns in series. A system of multiple detectors connected in series was used for the analysis. A multi-angle laser light scattering (MALS) detector (DAWNHELEOS II, Wyatt Technology Corporation, Goleta, CA), operating at a wavelength of $658 \mathrm{~nm}$, a viscometer detector (Viscostar, Wyatt Technology Corporation, Goleta, CA), and a refractive 
109

110

111

112

113

114

115

116

117

118

119

120

121

122

123

124

125

126

127

128

129

130

131

132

133

134

135

136

137

138

139

index detector operating at a wavelength of $658 \mathrm{~nm}$ (Optilab T-rEX, Wyatt Technology Corporation, Goleta, CA) provided online results. Data acquisition and analysis was conducted using Astra 6 software (Wyatt Technology Corporation, Goleta, CA). Monodisperse polystyrene standard $(\mathrm{Mw} \sim 21 \mathrm{k}, \mathrm{D} \sim 1.02)$ was run first in every sample series for the purpose of calibration and confirmation.

Preparation of Cellulose Acetate 10-Undecenoate (CA-Un067). The procedure for the preparation of CA-Un067 was modified from our previously published method (Meng, Matson \& Edgar, 2014a). In detail, CA-320S (1.00 g, 4.19 mmol/AGU) was dissolved in DMI (30 mL), and the solution was heated to $90^{\circ} \mathrm{C}$ with mechanical stirring under $\mathrm{N}_{2}$. Triethylamine $(1.29 \mathrm{~mL}$, 9.22 mmol, 2.2 equiv.) was added; a condenser was used to avoid evaporative loss of the base catalyst. 10-Undecenoyl chloride (1.70 g, $8.36 \mathrm{mmol}, 2.0$ equiv.) was added dropwise and allowed to react at $90{ }^{\circ} \mathrm{C}$ for $20 \mathrm{~h}$. The reaction mixture was then filtered, and the filtrate was

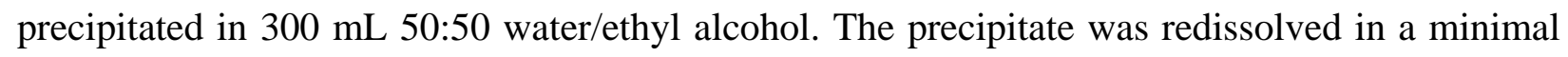
amount of $\mathrm{CH}_{2} \mathrm{Cl}_{2}$ and reprecipitated by addition to hexane. The product was washed with hexane and dried under vacuum at $40{ }^{\circ} \mathrm{C}$. Degrees of substitution (DS) by ${ }^{1} \mathrm{H}$ NMR: DS(undec10-enoate) (DS(Un)) 0.67, DS(acetate) (DS(Ac)) 1.88; yield: 1.27 g, 93\%.

Spectral assignments using CA-Un067 as an example: ${ }^{1} \mathrm{H}$ NMR (DMSO-d 6 ): 1.21 (br s, $\mathrm{COCH}_{2} \mathrm{CH}_{2} \underline{\mathrm{C}}_{2} \mathrm{C}_{2} \mathrm{C}_{2}{ }_{2} \underline{\mathrm{H}}_{2} \mathrm{CH}_{2} \mathrm{CH}_{2} \mathrm{CH}=\mathrm{CH}_{2}$ ), 1.32 (br s,

$\mathrm{COCH}_{2} \mathrm{CH}_{2} \mathrm{CH}_{2} \mathrm{CH}_{2} \mathrm{CH}_{2} \mathrm{CH}_{2} \mathrm{CH}_{2} \mathrm{CH}_{2} \mathrm{CH}=\mathrm{CH}_{2}$ ), 1.50 (br s, $\mathrm{COCH}_{2} \mathrm{CH}_{2} \mathrm{CH}_{2} \mathrm{CH}_{2} \mathrm{CH}_{2} \mathrm{CH}_{2} \mathrm{CH}_{2} \mathrm{CH}_{2} \mathrm{CH}=\mathrm{CH}_{2}$ ), 1.8-2.1(m, $\mathrm{COCH}_{2} \mathrm{CH}_{2} \mathrm{CH}_{2} \mathrm{CH}_{2} \mathrm{CH}_{2} \mathrm{CH}_{2} \mathrm{CH}_{2} \mathrm{CH}_{2} \mathrm{CH}=\mathrm{CH}_{2}$, and $\mathrm{COCH}_{3}$ ), 2.30 (br s, $\mathrm{COCH}_{2} \mathrm{CH}_{2} \mathrm{CH}_{2} \mathrm{CH}_{2} \mathrm{CH}_{2} \mathrm{CH}_{2} \mathrm{CH}_{2} \mathrm{C}_{2} \mathrm{CH}=\mathrm{CH}_{2}$ ), 3.3-5.3 (m, cellulose backbone), 4.8-5.0 (q, $\mathrm{COCH}_{2} \mathrm{CH}_{2} \mathrm{CH}_{2} \mathrm{CH}_{2} \mathrm{CH}_{2} \mathrm{CH}_{2} \mathrm{CH}_{2} \mathrm{CH}_{2} \mathrm{CH}=\mathrm{CH}_{2}$ ), 5.7 (m,

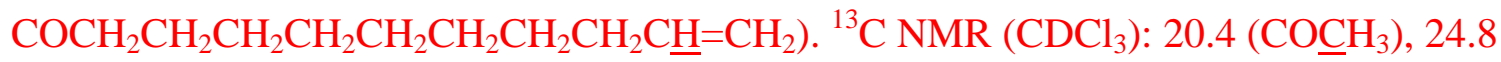

$\left(\mathrm{COCH}_{2} \mathrm{CH}_{2} \mathrm{CH}_{2} \mathrm{CH}_{2} \mathrm{CH}_{2} \mathrm{CH}_{2} \mathrm{CH}_{2} \mathrm{CH}_{2} \mathrm{CH}=\mathrm{CH}_{2}\right), 28.8$

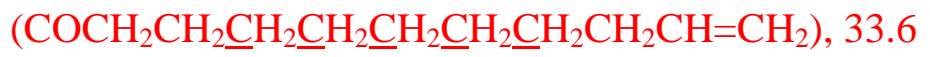

$\left(\mathrm{COCH}_{2} \mathrm{CH}_{2} \mathrm{CH}_{2} \mathrm{CH}_{2} \mathrm{CH}_{2} \mathrm{CH}_{2} \mathrm{CH}_{2} \mathrm{CH}_{2} \mathrm{CH}=\mathrm{CH}_{2}\right), 114.1$

$\left(\mathrm{COCH}_{2} \mathrm{CH}_{2} \mathrm{CH}_{2} \mathrm{CH}_{2} \mathrm{CH}_{2} \mathrm{CH}_{2} \mathrm{CH}_{2} \mathrm{CH}_{2} \mathrm{CH}=\underline{\mathrm{C}} \mathrm{H}_{2}\right), 139.0$

$\left(\mathrm{COCH}_{2} \mathrm{CH}_{2} \mathrm{CH}_{2} \mathrm{CH}_{2} \mathrm{CH}_{2} \mathrm{CH}_{2} \mathrm{CH}_{2} \mathrm{CH}_{2} \mathrm{CH}=\mathrm{CH}_{2}\right.$ ), 168.9-173.1 (C=O), $62.2(\mathrm{C}-6)$, 72.0-76.4 (C2, C3, C5), 82.3 (C-4), 100.7 (C-1). 

Exemplary procedure for olefin cross-metathesis reaction of CA-Un067 with acrylamides in THF. CA-Un067 (100 mg, $0.188 \mathrm{mmol}$ terminal olefin, 1.0 equiv.), $5 \mathrm{mg}$ BHT, and $4 \mathrm{~mL}$ THF were charged to a $25 \mathrm{~mL}$ three-neck round bottom flask. The mixture was stirred and purged with $\mathrm{N}_{2}$. After the reagents were fully dissolved, 20 equiv. of a cross-metathesis partner (e.g. acrylamide) was added into the flask, and dissolved, followed by the addition of HoveydaGrubbs' $2^{\text {nd }}$ generation catalyst $(3.6 \mathrm{mg}, 0.03$ equiv., dissolved in $2 \mathrm{~mL}$ of THF) which was added dropwise to the system by syringe. After stirring for $1 \mathrm{~h}$ under $\mathrm{N}_{2}$ at $30^{\circ} \mathrm{C}$, the reaction was stopped by adding 3 drops of diethylene glycol monovinyl ether. The product was collected by adding the reaction mixture to $100 \mathrm{~mL}$ of $\mathrm{H}_{2} \mathrm{O}$ to precipitate the product, which was collected by filtration and washed thoroughly by $\mathrm{H}_{2} \mathrm{O}$ before being dried under vacuum at $40{ }^{\circ} \mathrm{C}$.

\section{Exemplary procedure for olefin cross-metathesis reaction of CA-Un067 with acrylamides} in acetic acid. CA-Un067 (100 mg, $0.188 \mathrm{mmol}$ terminal olefin, 1.0 equiv.), $5 \mathrm{mg}$ of BHT and 4 $\mathrm{mL}$ of acetic acid were charged to a $25 \mathrm{~mL}$ three-neck round bottom flask. The mixture was stirred and purged with $\mathrm{N}_{2}$. After the reagents were fully dissolved, a certain amount (20 equiv.) of a cross-metathesis partner (e.g. acrylamide) was added into the flask and dissolved, followed by the addition of Hoveyda-Grubbs' $2^{\text {nd }}$ generation catalyst $(3.6 \mathrm{mg}, 0.03$ equiv., dissolved in 2 $\mathrm{mL}$ of acetic acid) which was added dropwise to the system by syringe. After stirring for $1 \mathrm{~h}$ under $\mathrm{N}_{2}$ at $30{ }^{\circ} \mathrm{C}$, the reaction was stopped by adding 3 drops of diethylene glycol monovinyl ether. The product was collected by precipitating in $100 \mathrm{~mL}$ of $\mathrm{H}_{2} \mathrm{O}$ (a small amount of $\mathrm{NaHCO}_{3}$ was added to facilitate the precipitation process), and washed thoroughly with $\mathrm{H}_{2} \mathrm{O}$ before being dried under vacuum at $40{ }^{\circ} \mathrm{C}$. The product at full conversion was named as CA-Un067-Aam. Spectral assignment using CA-Un067-Aam as an example: ${ }^{1} \mathrm{H}$ NMR (DMSO-d $)$ ): 1.21 (br s, $\mathrm{COCH}_{2} \mathrm{CH}_{2} \underline{\mathrm{CH}}_{2} \underline{\mathrm{CH}}_{2} \mathrm{C}_{2} \underline{\mathrm{C}}_{2} \mathrm{CH}_{2} \mathrm{CH}_{2} \mathrm{CH}=\mathrm{CH}_{2} \mathrm{CONH}_{2}$ ), 1.36 (br s, $\mathrm{COCH}_{2} \mathrm{CH}_{2} \mathrm{CH}_{2} \mathrm{CH}_{2} \mathrm{CH}_{2} \mathrm{CH}_{2} \mathrm{CH}_{2} \mathrm{CH}_{2} \mathrm{CH}=\mathrm{CH}_{2} \mathrm{CONH}_{2}$ ), 1.50 (br s, $\left.\mathrm{COCH}_{2} \mathrm{CH}_{2} \mathrm{CH}_{2} \mathrm{CH}_{2} \mathrm{CH}_{2} \mathrm{CH}_{2} \mathrm{CH}_{2} \mathrm{CH}_{2} \mathrm{CH}=\mathrm{CH}_{2} \mathrm{CONH}_{2}\right), 1.8-2.4(\mathrm{~m}$, $\mathrm{COCH}_{2} \mathrm{CH}_{2} \mathrm{CH}_{2} \mathrm{CH}_{2} \mathrm{CH}_{2} \mathrm{CH}_{2} \mathrm{CH}_{2} \underline{\mathrm{CH}}_{2} \mathrm{CH}=\mathrm{CH}_{2} \mathrm{CONH}_{2}$, and $\mathrm{COCH}_{3}$ ), 3.3-5.3 (m, cellulose backbone), 5.8 (d, $\mathrm{COCH}_{2} \mathrm{CH}_{2} \mathrm{CH}_{2} \mathrm{CH}_{2} \mathrm{CH}_{2} \mathrm{CH}_{2} \mathrm{CH}_{2} \mathrm{CH}_{2} \mathrm{CH}=\mathrm{CH}_{2} \mathrm{CONH}_{2}, E$ configuration), 6.6 (m, $\mathrm{COCH}_{2} \mathrm{CH}_{2} \mathrm{CH}_{2} \mathrm{CH}_{2} \mathrm{CH}_{2} \mathrm{CH}_{2} \mathrm{CH}_{2} \mathrm{CH}_{2} \mathrm{CH}=\mathrm{CH}_{2} \mathrm{CONH}_{2}, E$ configuration). ${ }^{13} \mathrm{C}$ NMR (DMSO$\left.\mathrm{d}_{6}\right): 20.9\left(\mathrm{CO}^{\mathrm{CH}} 3\right), 24.8\left(\mathrm{COCH}_{2} \underline{\mathrm{CH}}_{2} \mathrm{CH}_{2} \mathrm{CH}_{2} \mathrm{CH}_{2} \mathrm{CH}_{2} \mathrm{CH}_{2} \mathrm{CH}_{2} \mathrm{CH}=\mathrm{CH}_{2} \mathrm{CONH}_{2}\right), 28.8$ 


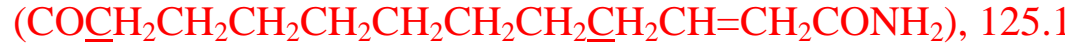

$\left(\mathrm{COCH}_{2} \mathrm{CH}_{2} \mathrm{CH}_{2} \mathrm{CH}_{2} \mathrm{CH}_{2} \mathrm{CH}_{2} \mathrm{CH}_{2} \mathrm{CH}_{2} \mathrm{CH}=\mathrm{CH}_{2} \mathrm{CONH}_{2}\right), 143.3$

$\left(\mathrm{COCH}_{2} \mathrm{CH}_{2} \mathrm{CH}_{2} \mathrm{CH}_{2} \mathrm{CH}_{2} \mathrm{CH}_{2} \mathrm{CH}_{2} \mathrm{CH}_{2} \mathrm{CH}=\mathrm{CH}_{2} \mathrm{CONH}_{2}\right)$, 167.0-173.1 (C=O), 62.2 (C-6), 72.076.4 (C2, C3, C5), 82.3 (C-4), 100.7 (C-1).

\section{Hydrogenation of the cross-metathesis product using $p$-toluenesulfonyl hydrazide. CA-} Un067-Aam (100 mg, $0.177 \mathrm{mmol}$ olefin, 1.0 equiv.), p-toluenesulfonyl hydrazide (164 mg, 5.0 equiv.), $10 \mathrm{mg}$ of BHT, $150 \mu \mathrm{LEt}_{3} \mathrm{~N}$ and $5 \mathrm{~mL}$ of DMF were charged to a 2 neck round bottom flask connecting with a reflux condenser. The mixture was stirred and purged with $\mathrm{N}_{2}$ at room temperature. After the reagents were dissolved, the mixture was heated to $135^{\circ} \mathrm{C}$ using an oil bath. The solution was stirred for $5 \mathrm{~h}$, then the reaction was stopped by cooling the flask in tap water. The product was collected by adding the reaction mixture slowly to $20 \mathrm{~mL}$ of EtOAc, and collecting the precipitate by filtration; it was then washed thoroughly using EtOAc, ethyl ether and $\mathrm{H}_{2} \mathrm{O}$. The product $(\mathrm{CA}-\mathrm{Un} 067-\mathrm{Aam}-\mathrm{H})$ was then dried under vacuum at $40{ }^{\circ} \mathrm{C} .{ }^{1} \mathrm{H} \mathrm{NMR}$ (DMSO-d $_{6}$ ): 1.24 (br s, $\mathrm{COCH}_{2} \mathrm{CH}_{2} \underline{\mathrm{CH}}_{2} \mathrm{C}_{2} \underline{\mathrm{CH}}_{2} \underline{\mathrm{CH}}_{2} \underline{\mathrm{CH}}_{2} \underline{\mathrm{C}}_{2} \mathrm{CH}_{2} \mathrm{CH}_{2} \mathrm{CONH}_{2}$ ), 1.48 (br s, $\mathrm{COCH}_{2} \mathrm{CH}_{2} \mathrm{CH}_{2} \mathrm{CH}_{2} \mathrm{CH}_{2} \mathrm{CH}_{2} \mathrm{CH}_{2} \mathrm{CH}_{2} \mathrm{CH}_{2} \mathrm{CH}_{2} \mathrm{CONH}_{2}$ ), 1.8-2.4 (m, $\mathrm{COCH}_{3}$, $\mathrm{COCH}_{2} \mathrm{CH}_{2} \mathrm{CH}_{2} \mathrm{CH}_{2} \mathrm{CH}_{2} \mathrm{CH}_{2} \mathrm{CH}_{2} \mathrm{CH}_{2} \mathrm{CH}_{2} \mathrm{CH}_{2} \mathrm{CONH}_{2}$ ), 2.75-5.25 (m, cellulose backbone), 6.75 and 7.25 (br s, $\mathrm{COCH}_{2} \mathrm{CH}_{2} \mathrm{CH}_{2} \mathrm{CH}_{2} \mathrm{CH}_{2} \mathrm{CH}_{2} \mathrm{CH}_{2} \mathrm{CH}_{2} \mathrm{CH}_{2} \mathrm{CH}_{2} \mathrm{CONH}_{2}$ ). ${ }^{13} \mathrm{C} \mathrm{NMR}$ (DMSO-d 6 ): $20.9\left(\mathrm{COCH}_{3}\right), 25.5\left(\mathrm{COCH}_{2} \mathrm{CH}_{2} \mathrm{CH}_{2} \mathrm{CH}_{2} \mathrm{CH}_{2} \mathrm{CH}_{2} \mathrm{CH}_{2} \mathrm{CH}_{2} \mathrm{CH}_{2} \mathrm{CH}_{2} \mathrm{CONH}_{2}\right), 28.9$ $\left(\mathrm{COCH}_{2} \underline{\mathrm{CH}_{2}} \underline{\mathrm{CH}}_{2} \underline{\mathrm{CH}_{2}} \underline{\mathrm{CH}_{2}} \underline{\mathrm{CH}_{2}} \underline{\mathrm{CH}}_{2} \underline{\mathrm{CH}_{2}} \underline{\mathrm{CH}_{2}} \mathrm{CH}_{2} \mathrm{CONH}_{2}\right), 35.6$

$\left(\mathrm{COCH}_{2} \mathrm{CH}_{2} \mathrm{CH}_{2} \mathrm{CH}_{2} \mathrm{CH}_{2} \mathrm{CH}_{2} \mathrm{CH}_{2} \mathrm{CH}_{2} \mathrm{CH}_{2} \mathrm{CH}_{2} \mathrm{CONH}_{2}\right), 174.8$ $\left(\mathrm{COCH}_{2} \mathrm{CH}_{2} \mathrm{CH}_{2} \mathrm{CH}_{2} \mathrm{CH}_{2} \mathrm{CH}_{2} \mathrm{CH}_{2} \mathrm{CH}_{2} \mathrm{CH}_{2} \mathrm{CH}_{2} \mathrm{CONH}_{2}\right.$ ), 169.1-173.3 (C=O), 63.0 (C-6), 72.076.4 (C2, C3, C5), 80.4 (C-4), 100.0 (C-1). Yield: 72 mg, $72 \%$.

\section{Results and Discussion}

Olefin cross-metathesis has been proven a useful tool for polysaccharide chemists, in which polysaccharide derivatives (e.g. cellulose derivatives) with terminally olefinic side-chain react with different $\mathrm{CM}$ partners such as acrylic acid and its esters. With the help of this chemistry, we (Dong \& Edgar, 2015; Meng, Matson \& Edgar, 2014a, b) and others (Malzahn, Marsico, Koynov, Landfester, Weiss \& Wurm, 2014) have been able to introduce a variety of functional groups onto polysaccharide backbone in a mild, modular and efficient manner. In the current study, we examined the feasibility of using acrylamides as CM partners to obtain 
201 cellulose esters bearing amide functionalities, by the reaction scheme illustrated by Figure 2. 202 Terminally olefinic cellulose esters were used as the substrates for CM reaction, for example 203 cellulose undec-10-enoate with DS(Un) 0.67 (CA-Un067). The alkene side chain serves as the 204 reactive site for CM reaction. Hoveyda-Grubbs' $2^{\text {nd }}$ generation catalyst (HG-2), which has been 205 proven tolerant to many functional groups, was chosen as the catalyst.

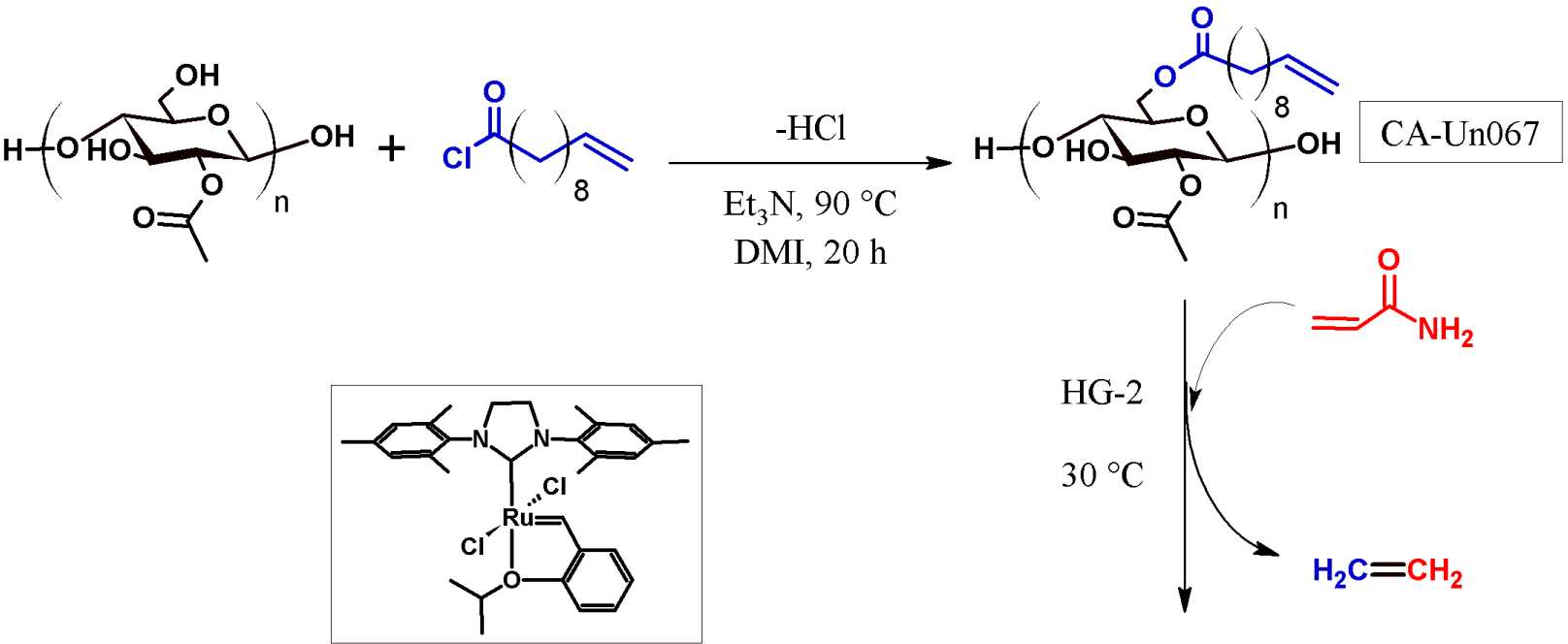

Hoveyda-Grubbs $2^{\text {nd }}$ gen. catalyst

(HG-2)

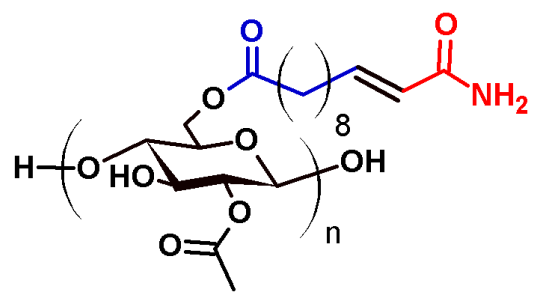

207 Figure 2. General scheme of cross-metathesis reaction of terminally olefinic cellulose ester CA208 Un067 with acrylamide. Note that structures are not meant to imply regiospecificity; particular 209 positions of substitution in all schemes are only for convenience of depiction and clarity.

We selected THF as solvent for our initial studies (Table 1), as it has been demonstrated to be useful for $\mathrm{CM}$ reactions of cellulose esters with a variety of partners (Meng, Matson \& 212 Edgar, 2014a, b). Proton NMR was employed to monitor the conversion of CM reactions. As the 213 reaction proceeds, the terminal olefin signals of the starting polymer at around 4.90 and 5.75 214 ppm decrease and the signals of newly formed $\alpha, \beta$-unsaturation at 5.84 and 6.60 ppm increase 215 (Figure 5). In contrast to the 100\% conversion achieved in CM of CA-Un067 with acrylic acid, 216 only $15 \%$ conversion to $\mathrm{CM}$ product was achieved when acrylamide was employed as $\mathrm{CM}$ 217 partner (Table 1, entries 1 and 2) under the same reaction conditions. Varying reaction 
218 parameters including catalyst loading, addition method, reaction time and the CM partner ratio 219 did afford some improvement in reaction conversion, in logical fashion. For example, increasing 220 reaction time from $1 \mathrm{~h}$ to $3 \mathrm{~h}$ improved conversion from $15 \%$ to $22 \%$, while the conversion was $22128 \%$ upon increasing catalyst loading from 3 to 6 mol\%. The best conversion in THF (50\%) was 222 realized by adding a second charge of $6 \mathrm{~mol} \%$ catalyst after $3 \mathrm{~h}$ (Table 1, entry 6). However, it 223 was not possible to achieve acceptably high conversion at reasonable catalyst levels.

224 Table 1. Olefin cross-metathesis reactions of terminally olefinic cellulose ester CA-Un067 with 225 acrylamide and acrylic acid in THF. ${ }^{\text {a }}$

\begin{tabular}{|c|c|c|c|c|c|}
\hline Entry \# & $\begin{array}{c}\text { Cat. Loading } \\
(\text { mol \%) }\end{array}$ & CM partner & Olefin ratio $^{b}$ & $\begin{array}{l}\text { Time } \\
\text { (h) }\end{array}$ & Conversion to $\mathrm{CM}^{\mathrm{c}}$ \\
\hline $1^{\mathrm{d}}$ & 3 & acrylic acid & 20 & 1 & $100 \%$ \\
\hline 2 & 3 & acrylamide & 20 & 1 & $15 \%$ \\
\hline 3 & 3 & acrylamide & 20 & 3 & $22 \%$ \\
\hline 4 & 6 & acrylamide & 20 & 1 & $28 \%$ \\
\hline 5 & 12 & acrylamide & 40 & 16 & $43 \%$ \\
\hline $6^{\mathrm{e}}$ & $6+6$ & acrylamide & 40 & $3+3$ & $50 \%$ \\
\hline
\end{tabular}

$226{ }^{\mathrm{a}}$ All reactions were performed at $30^{\circ} \mathrm{C}$ in THF using $\mathrm{HG}-2$ catalyst. ${ }^{\mathrm{b}} \mathrm{Mol}$ ratio of CM partner to 227 olefin side chain on cellulose backbone. ${ }^{\mathrm{c}}$ Determined by ${ }^{1} \mathrm{H}$ NMR spectroscopy. ${ }^{\mathrm{d}}$ Ref. $16 .{ }^{\mathrm{e}} 6 \mathrm{~mol} \%$ 228 of HG-2 was added into the system; after reacting for $3 \mathrm{~h}$, another 6 mol\% was added, then 229 reaction was continued for an additional $3 \mathrm{~h}$. 


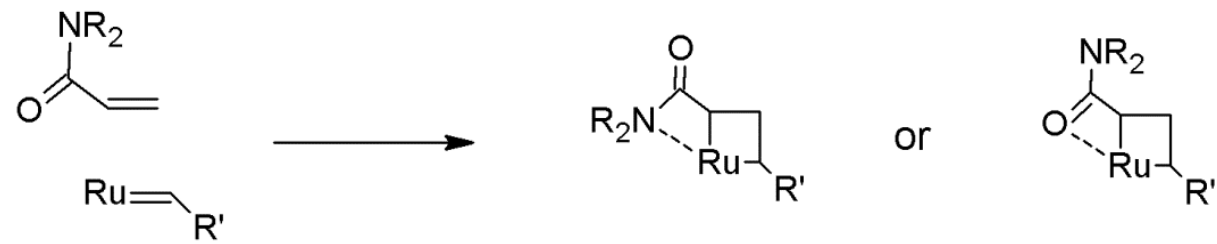

Figure 3. Proposed amide chelation of the catalyst in CM reactions with acrylamides.

Low conversion in CM reactions between $\alpha, \beta$-unsaturated amides, especially electronrich amides, and terminal olefins has been observed by several groups (Choi, Chatterjee \& Grubbs, 2001; Formentin, Gimeno, Steinke \& Vilar, 2005). The Grubbs group suggested that for amides (especially electron-rich ones), the carbonyl group can chelate to the metal center of the catalyst and thereby decrease catalyst turnover. Such chelation effects are not unprecedented in olefin metathesis. Similar effects have also been observed during olefin metathesis of aminecontaining systems (Compain, 2007). Based on these studies, we believe the low observed conversion may be a result of coordination between the Ru atom of the HG-2 catalyst and the carbonyl or amine group of the amide, as shown in Figure 3. While the problematic amine group can be masked by protecting groups or by in situ formation of ammonium salts with the help of acid additives (Compain, 2007; Formentin, Gimeno, Steinke \& Vilar, 2005), this is not an option for amides, which are not sufficiently basic to readily form salts and for which protection/deprotection techniques are limited. However, based on the proposed chelation mechanism, it is reasonable to speculate that any factors that can lower the effective electron density on the amide would weaken the potential for chelation and thus increase the metathesis activity. We hypothesized that by using acetic acid as a solvent, the resulting solvation shell around the amide functional group, stabilized by H-bonding, may help minimize amide-Ru chelation and thereby enhance conversion.

Table 2. Olefin CM reactions of terminally olefinic cellulose ester CA-Un067 with acrylamide in acetic acid. ${ }^{\mathrm{a}}$

\section{Entry \# Cat. Loading CM partner Olefin ratio ${ }^{b}$ Time Conversion}

$(\mathbf{m o l} \%)$

(h) 


\begin{tabular}{cccccc}
\hline 7 & 6 & Acrylamide & 20 & 1 & $81 \%$ \\
8 & 6 & Acrylamide & 20 & 3 & $85 \%$ \\
$9^{\mathrm{d}}$ & $6+6$ & Acrylamide & 20 & $1+1$ & $94 \%$ \\
$10^{\mathrm{d}}$ & $6+6$ & Acrylamide & 40 & $1+1$ & $99 \%$ \\
\hline
\end{tabular}

252 a All reactions were performed at $30{ }^{\circ} \mathrm{C}$ in acetic acid using HG-2 catalyst. ${ }^{b} \mathrm{Mol}$ ratio of 253 acrylamide to olefin on cellulose. ${ }^{\mathrm{c}}$ Determined by ${ }^{1} \mathrm{H}$ NMR spectroscopy. ${ }^{\mathrm{d}} 6 \mathrm{~mol} \%$ of HG-2 was 254 added initially; after reacting for $1 \mathrm{~h}$, another 6 mol\% was added and stirring continued $1 \mathrm{~h}$ more 255 before the reaction was stopped.

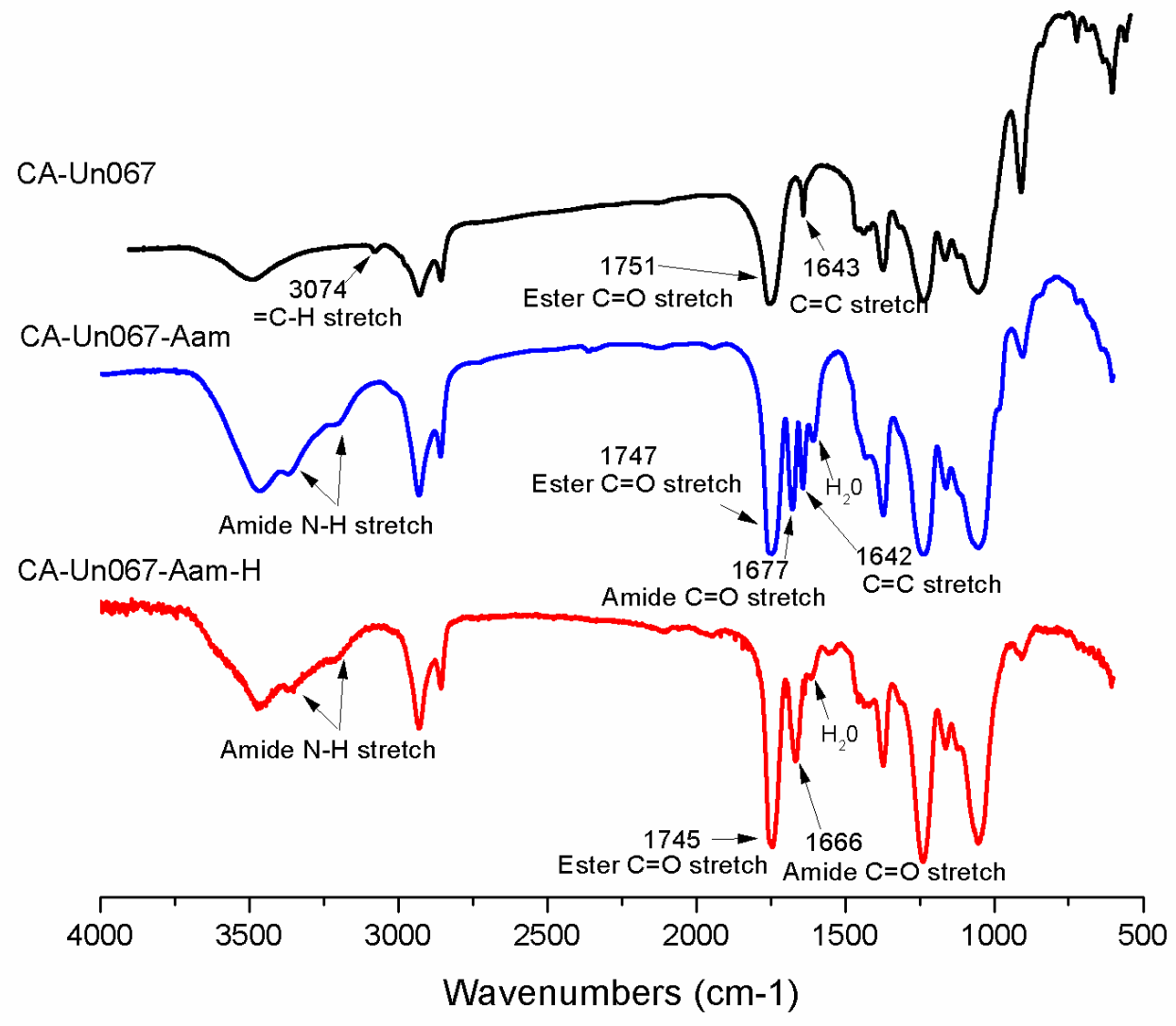

257 Figure 4. FTIR spectra of CA-Un067, CA-Un067-Aam (Entry 10, Table 2) and its hydrogenated 258 product CA-Un067-Aam-H. 
Switching from THF to acetic acid as the solvent significantly improved CM efficiency (Table 2). For example, while in THF only $28 \%$ conversion to CM was achieved for entry 4 in Table 1, 81\% conversion was attained when acetic acid was used as the solvent under otherwise equivalent reaction conditions (Entry 7, Table 2; $6 \mathrm{~mol} \% \mathrm{HG}-2,20$ equiv. acrylamide, $30{ }^{\circ} \mathrm{C}, 1 \mathrm{~h}$ ). Conversion of about $80 \%$ may be a perfectly acceptable result, depending on the application envisioned and on the pertinent structure-property relationship. However, for certain types of polymer post-modification, it is important to identify conditions that permit quantitative transformation; for example in some biomedical applications, where complete knowledge of the polymer structure is advantageous to obtaining regulatory approval. In pursuit of such conditions that would permit complete conversion of acrylamide, a second $6 \mathrm{~mol} \%$ charge of catalyst was added after $60 \mathrm{~min}$ of reaction, and the mixture allowed to react for an additional $1 \mathrm{~h}$; this methodology afforded $94 \%$ conversion. To further push the reaction towards completion, the amount of acrylamide was increased to 40 equiv., and thereby over $99 \%$ conversion was achieved. As shown in the FTIR spectra in Figure 4, the $=\mathrm{C}-\mathrm{H}$ stretch peak at $3071 \mathrm{~cm}^{-1}$ for the terminal olefin of the start polymer (CA-Un067) completely disappeared in the spectrum of the complete conversion CM product (CA-Un067-Aam). Two shoulder peaks at 3230 and $3370 \mathrm{~cm}^{-1}$ were assigned to amide N-H stretch signals, while a new peak at $1677 \mathrm{~cm}^{-1}$, which was assigned to amide $\mathrm{C}=\mathrm{O}$ stretch, was additional evidence of successful $\mathrm{CM}$ reaction. More evidence was provided by proton NMR spectra. As shown in Figure 5, the terminal olefin signals at 4.90 and $5.75 \mathrm{ppm}$ in the ${ }^{1} \mathrm{H}$ NMR spectrum of polymer 10 (CA-Un067-Aam) completely disappeared, while new signals corresponding to the $\alpha, \beta$-unsaturated olefin appeared at 5.90 and $6.65 \mathrm{ppm}(E$ configuration, no $Z$ configuration signals were detected). The two broad and weak signals at 6.7 and $7.3 \mathrm{ppm}$ in the spectrum of CA-Un067-Aam were assigned to amide proton resonances. The full and clean conversion achieved under these $\mathrm{CM}$ conditions was further proven by ${ }^{13} \mathrm{C}$ NMR spectroscopy, with the complete disappearance of terminal olefin carbon signals at 114 and 139 ppm, and the new peaks at 125 and 143 ppm corresponding to the $\alpha, \beta$-carbons of the new olefin (Figure 6).

Cellulose esters bearing other alkanoate substituents were also tested as CM substrates. These included cellulose acetate propionate undec-10-enoate, cellulose acetate butyrate undec10-enoate, and cellulose acetate pent-4-enoate, which has a shorter olefinic side chain than its undecenoate counterparts (Supporting Information S1 and S2). Gratifyingly high coupling 
290 efficiencies (up to 95\%) were also achieved with these substrates using acetic acid as solvent by 291 procedures analogous to that for reaction of CAUn067 with acrylamide (described in the 292 Experimental Section), showing the flexibility of this CM approach with regard to alkanoate 293 substitution. As it has been reported that Grubbs catalysts are tolerant to many protic solvents 294 (Adjiman, Clarke, Cooper \& Taylor, 2008; Schulz \& Wagener, 2012), it would not be surprising 295 if the approach could be extended to other polysaccharide derivatives, as long as they are soluble 296 in solvents such as acetic acid.

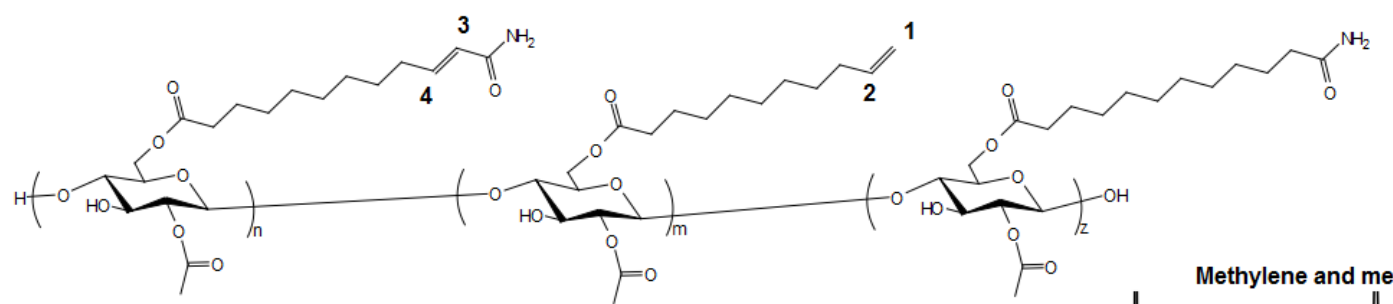

CA-Un067-Aam

CA-Un067

CA-Un067-Aam-H
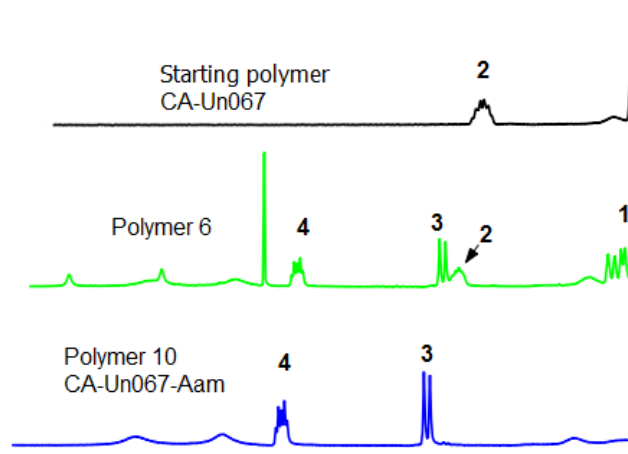

Hydrogenated product CA-Un067-Aam-H
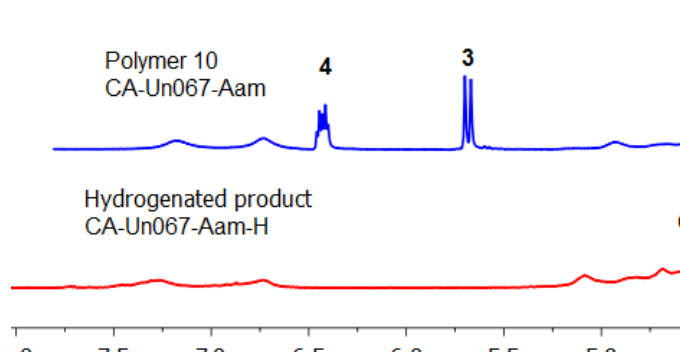

0

298 Figure 5. Representative ${ }^{1} \mathrm{H}$ NMR spectra of CA-Un067, incomplete CM product polymer 6, 299 complete CM product polymer 10 (CA-Un067-Aam) and its hydrogenated product CA-Un067300 Aam-H. 

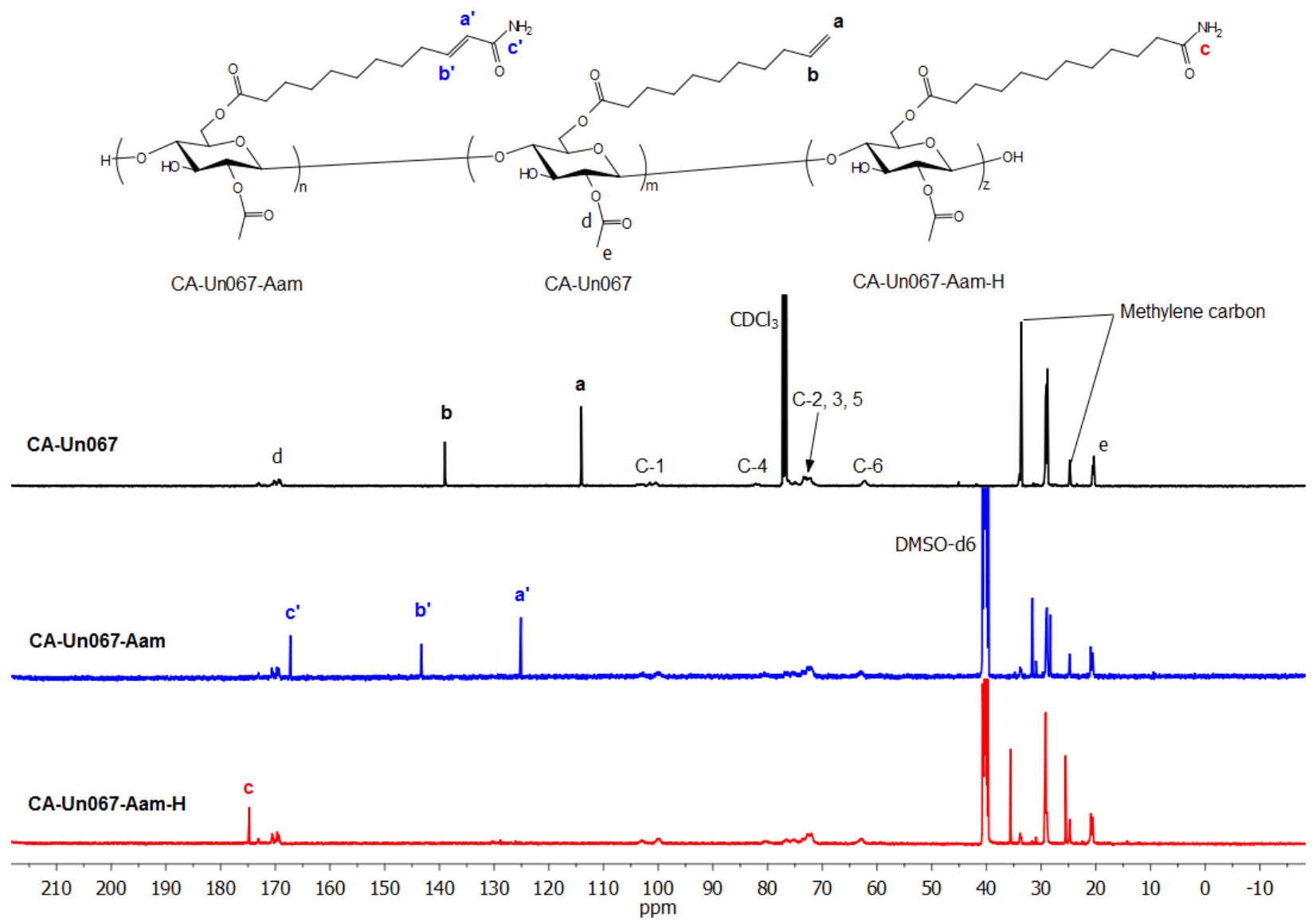

Figure 6. ${ }^{13} \mathrm{C}$ NMR spectra of CA-Un067, complete CM product polymer 10 (CA-Un067-Aam) and its hydrogenated product CA-Un067-Aam-H.

In our previous study (Meng, Matson \& Edgar, 2014a), crosslinking was observed for 305 CM products during storage, which we attributed to radical abstraction of $\gamma$-hydrogens of the $\alpha, \beta$-unsaturated $\mathrm{CM}$ product, followed by condensation reactions (e.g. radical-radical coupling, addition to double bonds) of the radicals so produced, resulting in crosslinking. The same phenomenon was also observed for the acrylamide products of this study. We reported the success of both heterogeneous and homogeneous catalytic hydrogenation methods in THF to eliminate the crosslinking potential of acrylic acid and acrylic ester CM products, by saturating 311 the double bond (Meng, Matson \& Edgar, 2014b). Unfortunately, these methods were not useful 312 for the amide CM polymers of this study, as they are no longer soluble in commonly used 313 hydrogenation solvents such as THF after being isolated and dried. Hence, we sought a more 314 universal method for hydrogenation of CM product olefins, and for that reason began to 315 investigate diimide (generated in situ by thermolysis of $p$-toluenesulfonyl hydrazide) as the 
hydrogen source, using the more powerful solvent DMF for these amide CM products (Hahn, 1992). As the CM conversions of all other polymers shown in Table 1, 2 and 3 were incomplete, only the polymer from entry 10 in Table 2 (CA-Un067-Aam, conversion 99\%) was used for proof of concept experiments on diimide hydrogenation. As shown in Figure 7, 5 equivalents of p-toluenesulfonyl hydrazide in DMF completely hydrogenated CA-Un067-Aam within $5 \mathrm{~h}$ at $135^{\circ} \mathrm{C}$, to give the final product (CA-Un067-Aam-H). The FTIR spectrum in Figure 4 showed the disappearance of the $\mathrm{C}=\mathrm{C}$ stretch, while the amide $\mathrm{C}=\mathrm{O}$ stretch redshifted from 1677 to 1666 $\mathrm{cm}^{-1}$, due to the elimination of the $\alpha, \beta$-unsaturation. The proton and carbon NMR spectra in Figure 5 and Figure 6 showed complete disappearance of the olefin signals, confirming quantitative hydrogenation.

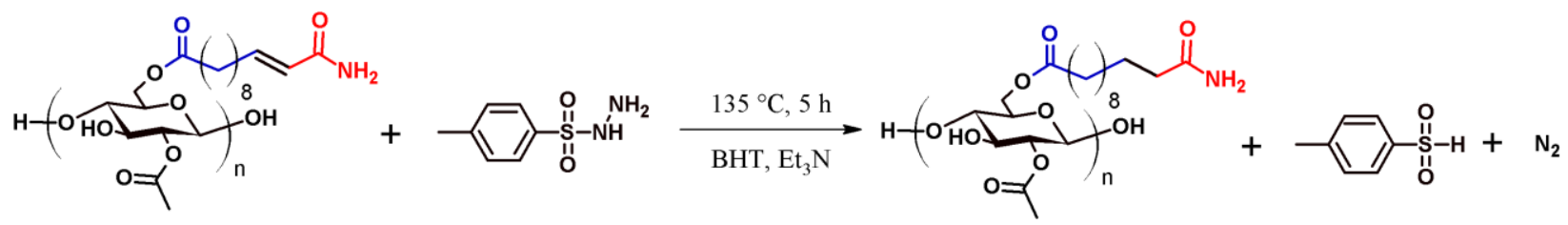

Figure 7. Hydrogenation of CA-Un067-Aam by $p$-toluenesulfonyl hydrazide.

As the acidic solvent (acetic acid) used in the $\mathrm{CM}$ reaction, and the temperature $\left(135^{\circ} \mathrm{C}\right)$ in the following hydrogenation reaction are potentially detrimental to anomeric and ester linkages of the cellulose derivatives, it was necessary to examine the degree of substitution of the ester moieties and the impact on polymer DP after these reactions. From the integrals of the ${ }^{1} \mathrm{H}$ NMR spectrum of CA-Un067-Aam-H (Supporting Information S3), DS(Ac) 1.90 and $\mathrm{DS}$ (amide) $\sim 0.66$. The DS(Ac) was close to its original value, indicating that the ester moieties were well preserved during $\mathrm{CM}$ and hydrogenation reactions.

It is quite noteworthy that after $\mathrm{CM}$ and hydrogenation, the molecular weight as well as PDI of the CA-Un067-Aam-H remained almost unchanged (slightly increased due to the grafting of amide functionality) compared with those of the starting cellulose ester CA-Un067, as shown in the SEC chromatograms (Figure 8). Even though the CM reaction was performed in acetic acid and the hydrogenation was performed at $135^{\circ} \mathrm{C}$, chain scission was negligible.

It is also intriguing that in contrast with CA-Un067, which exhibits a $\mathrm{T}_{\mathrm{g}}$ at $128^{\circ} \mathrm{C}, \mathrm{CA}$ Un067-Aam-H showed an endothermic DSC transition at $139^{\circ} \mathrm{C}$, as shown in Figure 9. In our 
342 previous studies (Meng, Matson \& Edgar, 2014a, b), glass transition temperatures of products 343 after cross-metathesis reaction (with CM partners such as acrylic acid, 2-hydroxyethyl acrylate, 344 acrylate methyl and poly(ethylene glycol) methyl acrylate) decreased compared with $\mathrm{T}_{\mathrm{g}}$ values of 345 the corresponding starting terminally olefinic cellulose esters, which we described as a result of 346 the plasticizing effect of the relatively long-chain, partly hydrophobic grafted functional group 347 (Glasser, Samaranayake, Dumay \& Davé, 1995; Meng, Matson \& Edgar, 2014b) ${ }^{26}$. However, in 348 the current study the endothermic transition we observe occurs at temperatures significantly 349 higher than those of the previously studied cellulose alkanoate esters. As amides are known to be 350 able to form strong intermolecular and intramolecular hydrogen bonds (Gellman, Dado, Liang \& 351 Adams, 1991), we believe this H-bonding restricts backbone segmental motion, thus leading to 352 higher temperature transitions.

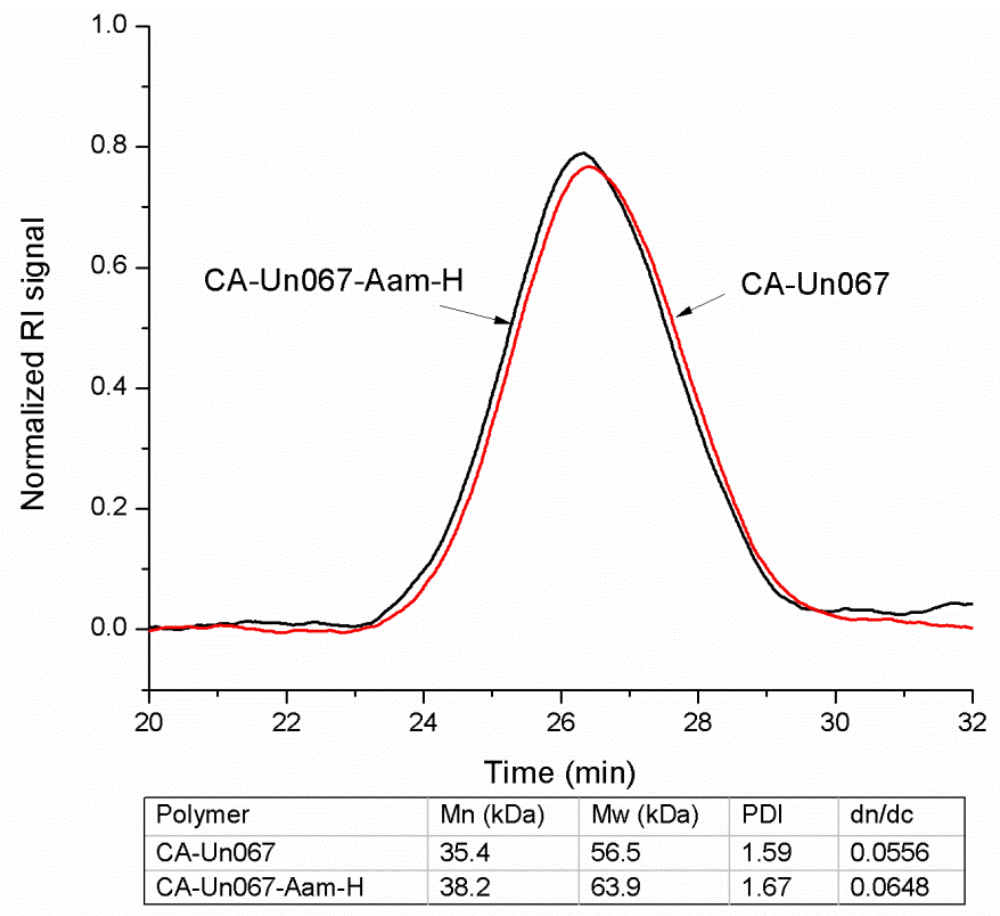

354 Figure 8. SEC traces of the starting cellulose ester (CA-Un067) and the final product after 355 complete CM with acrylamide and hydrogenation (CA-Un067-Aam-H). 


\section{CA-Un067-Aam-H}
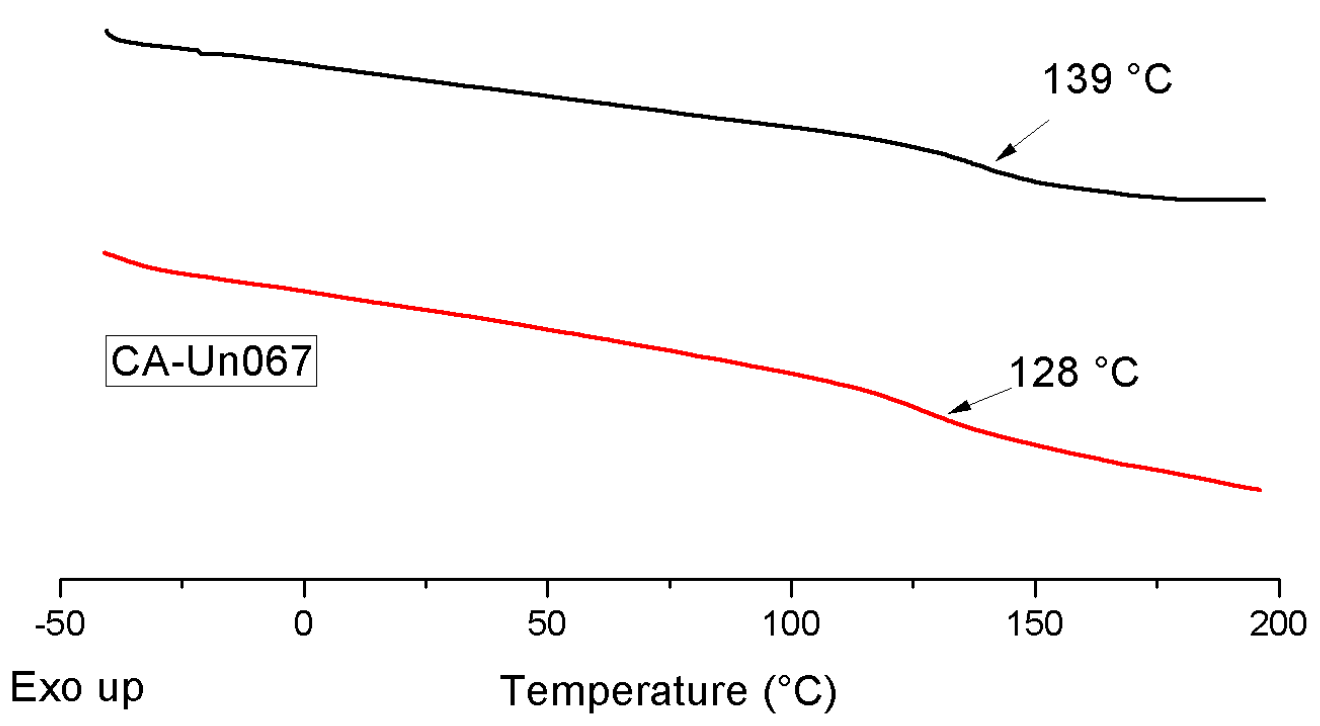

357 Figure 9. DSC analysis of the starting cellulose ester (CA-Un067) and the final product after complete CM with acrylamide followed by hydrogenation (CA-Un067-Aam-H).

With the success of CM with acrylamide in acetic acid, we wished to explore the effect of substitution at the amide nitrogen. We compared the effects of the two solvents (THF and acetic acid) on a series of acrylamide partners, including $N, N$-dimethyl acrylamide, $N$-isopropyl

362 acrylamide and $N$-phenyl acrylamide, trying to better understand these interactions and 363 rationalize the underlying principles. As shown in Table 3, solvents had different impacts upon 364 CM conversion, depending on acrylamide structure. In our hypothesis, acetic acid interacts with 365 acrylamides (likely via H-bonding) and so weakens the coordination between amide 366 functionality and ruthenium metal center, which then contributes to increasing the conversion of 367 the reaction. The results of CM with acrylamide and $N, N$-dimethyl acrylamide supported this 368 hypothesis, in which using acetic acid as solvent dramatically improved CM conversion relative 369 to reaction in THF. For CM with $N$-isopropyl acrylamide and $N$-phenyl acrylamide, acetic acid 
lowered the conversions, which at first seemed contradictory with regard to our previous hypothesis.

However, cross-metathesis is a complex process and the conversion to CM product is the result of multiple interactions between catalyst, solvent and $\mathrm{CM}$ substrates. In the case of $\mathrm{CM}$ with acrylamides, reaction conversion is principally influenced by two factors: the electron density of the partner (non-cellulosic) double bond, and the chelation ability of the amide. High electron density of the double bond and low chelation ability should lead to high conversion. Acrylamide $N$-substituents could affect the electron density of the double bond by electronic effects. On the other hand, they may also affect the chelation ability of the amide by changing electron density on the carboxamide oxygen and nitrogen atoms, and by steric effects (substituents with larger steric bulk may interfere with chelation with the metal center).

Taking all these factors into consideration, our results can be interpreted in a rational manner. In THF, for $N, N$-dimethyl acrylamide, the $N$-methyls are electron-donating, which increases electron density on both the nitrogen atom and the olefin. The electron density increase on nitrogen is likely more significant than that on the olefin, enhancing chelation, with the overall effect of lower conversion (39\%) than that for acrylamide $(50 \%)$. In the case of $\mathrm{N}$ isopropylacrylamide, conversion as high as $82 \%$ was achieved in THF. This can be explained by the steric bulk of the isopropyl group, which weakens chelation between the amide and $\mathrm{Ru}$, while the electron-donating effect is not sufficient to overcome the steric effect. For $\mathrm{N}$ phenylacrylamide, steric hindrance as well as the electron-withdrawing influence of the phenyl substituent act in concert to minimize amide- $\mathrm{Ru}$ coordination, but the strong electronwithdrawing effect of the phenyl group also contributes to lowering the electron density on the olefin. These influences balance one another, and the result is 50\% conversion for $\mathrm{N}$ phenylacrylamide (entry 18), the same as achieved with acrylamide in the same solvent. When the reactions were performed in acetic acid, electron density on both olefin and nitrogen/oxygen was reduced. For acrylamide and $N, N$-dimethylacrylamide, the chelation effect dominates the impact upon conversion. Acetic acid solvent improved the conversion of both acrylamide and $\mathrm{N}, \mathrm{N}$-dimethyl acrylamide partners to a large degree (entries 13, 15). However, for $\mathrm{N}$ isopropylacrylamide and $N$-phenylacrylamide, the chelation effects of which have already been minimized by the steric bulk of the $N$-substituent, running the reaction in acetic acid had its 
400 impact mostly by reducing the olefin electron density, thereby affording lower conversion 401 (entries 17, 19).

402 Table 3. Olefin cross-metathesis reactions of terminally olefinic cellulose ester CA-Un067 with 403 different acrylamides in acetic acid and THF. ${ }^{\mathrm{a}}$

\begin{tabular}{|c|c|c|c|}
\hline Entry \# & CM partner & Solvent & Conversion $^{b}$ \\
\hline 12 & & $\mathrm{THF}$ & $50 \%$ \\
\hline 13 & & HOAc & $95 \%$ \\
\hline 14 & & THF & $39 \%$ \\
\hline 15 & & HOAc & $68 \%$ \\
\hline 16 & & THF & $82 \%$ \\
\hline 17 & & HOAc & $73 \%$ \\
\hline 18 & & $\mathrm{THF}$ & $50 \%$ \\
\hline 19 & & HOAc & $37 \%$ \\
\hline
\end{tabular}

$404{ }^{\mathrm{a}}$ All reactions were conducted under same conditions: $50 \mathrm{mg}$ CA-Un067 (0.094 mmol olefin, 1 405 equiv.), $3 \mathrm{mg}$ BHT; CM partner: 40 equiv.; catalyst: 6 mol\% + 6 mol\% HG2; reaction time: $1 \mathrm{~h}$ 
$406+1 \mathrm{~h}$; temperature: $30^{\circ} \mathrm{C}$. ${ }^{\mathrm{b}}$ Conversion determined by proton NMR (Supporting Information S4, $407 \quad$ S5 and S6).

408 


\section{Conclusions}

Acrylamides as cross-metathesis partners generally afforded low conversion to $\mathrm{CM}$ products in neutral solvents such as THF, due to chelation between the amide functional group and the ruthenium metal center. Employing acetic acid as solvent for CM reactions of terminally olefinic cellulose esters had rationally explicable effects on improving CM conversion of acrylamides. For acrylamides with small substituents such as acrylamide and $N, N$ dimethylacrylamide, acetic acid significantly improved the CM conversion of these partners. We rationalize this effect as resulting from the fact that acetic acid can interact with the amide through $\mathrm{H}$-bonding, thereby weakening chelation of Ru by the amide. For acrylamides with large and/or electron-withdrawing substituents such as $\mathrm{N}$-isopropylacrylamide and $\mathrm{N}$ phenylacrylamide, low electron density on oxygen and nitrogen atoms of the amide and large steric bulk of the substituent(s) reduce amide chelation of Ru in either solvent. In these cases, using acetic acid as a solvent could not further improve the conversion, but might rather decrease the $\mathrm{CM}$ reactivity of the corresponding acrylamide by reducing olefin electron density. We believe that this methodology may prove generally useful for enhancing conversion of $\mathrm{CM}$ reactions of properly chosen acrylamides with other polysaccharides or other polymers containing appropriately designed olefinic substituents.

We also found an effective method for eliminating the unsaturation of the amide CM products of cellulose esters, by hydrogenation with diimide generated in situ by thermolysis of $p$ toluenesulfonyl hydrazide. This method is of particular importance for polymers that are not compatible with other catalytic hydrogenation methods, either due to solubility or reactivity (in some cases it can be difficult for rigid polysaccharide derivatives, especially those with bulky substituents, to interact effectively with the catalyst surface of a heterogeneous catalyst). We believe that this diimide hydrogenation method may prove to be of general utility for reducing the unsaturation of polysaccharide CM products. The conditions of the CM reaction in acetic acid as well as those of the hydrogenation were so mild that no significant molecular weight change or alkanoate hydrolysis was observed. The amide-functionalized cellulose esters showed thermal transitions that occurred at higher temperatures than those observed for cellulose longchain alkanoate derivatives. We postulate that H-bonding between amide substituents likely 
restricted segmental motion of the cellulose main chain and resulted to higher glass transition temperature.

\section{Acknowledgements}

We thank the Eastman Chemical Company for their kind donation of the commercial cellulose esters used in this work. We thank the National Science Foundation for partially funding this work through Grant DMR-1308276, the Institute for Critical Technologies and Applied Science at Virginia Tech for facility and financial support, and the Macromolecules and Interfaces Institute of Virginia Tech for educational support. We thank Prof. John Matson for helpful discussions. We also thank Mr. Mark Flynn and Ms. Shreya Choudhury of Virginia Tech for their help with SEC analyses, and Ms. Joyann Marks in our group for her help with DSC analyses.

\section{Supporting Information}

FTIR and NMR data of new compounds not included in the body of the manuscript, as well as descriptions of preparation of CAPUn, CABUn, and CAPen can be obtained in the supporting information.

\section{References}

Adjiman, C. S., Clarke, A. J., Cooper, G., \& Taylor, P. C. (2008). Solvents for ring-closing metathesis reactions. Chemical Communications(24), 2806-2808.

Barrett, A. G. M., Hennessy, A. J., Vézouët, R. L., Procopiou, P. A., Seale, P. W., Stefaniak, S., Upton, R. J., White, A. J. P., \& Williams, D. J. (2004). Synthesis of diverse macrocyclic peptidomimetics utilizing ring-closing metathesis and solid-phase synthesis. The Journal of Organic Chemistry, 69(4), 1028-1037.

Benkaddour, A., Journoux-Lapp, C., Jradi, K., Robert, S., \& Daneault, C. (2014). Study of the hydrophobization of TEMPO-oxidized cellulose gel through two routes: amidation and esterification process. Journal of Materials Science, 49(7), 2832-2843.

Choi, T. L., Chatterjee, A. K., \& Grubbs, R. H. (2001). Synthesis of alpha,beta-unsaturated amides by olefin cross-metathesis. Angewandte Chemie-International Edition, 40(7), 1277-1279. Compain, P. (2007). Olerin metathesis of amine-containing systems: Beyond the current consensus. Advanced Synthesis \& Catalysis, 349(11-12), 1829-1846.

Dong, Y., \& Edgar, K. J. (2015). Imparting functional variety to cellulose ethers via olefin crossmetathesis. Polymer Chemistry.

Formentin, P., Gimeno, N., Steinke, J. H. G., \& Vilar, R. (2005). Reactivity of Grubbs' catalysts with urea- and amide-substituted olefins. Metathesis and isomerization. Journal of Organic Chemistry, 70(20), 8235-8238. 
Gellman, S. H., Dado, G. P., Liang, G. B., \& Adams, B. R. (1991). Conformation-directing effects of a single intramolecular amide-amide hydrogen-bond - variable-temperature NMR and IR studies on a homologous diamide series. Journal of the American Chemical Society, 113(4), 1164-1173. Glasser, W. G., Samaranayake, G., Dumay, M., \& Davé, V. (1995). Novel cellulose derivatives. III. Thermal analysis of mixed esters with butyric and hexanoic acid. Journal of Polymer Science Part B: Polymer Physics, 33(14), 2045-2054. Grubbs, R. H. (2004). Olefin metathesis. Tetrahedron, 60(34), 7117-7140. Hagler, A. T., Huler, E., \& Lifson, S. (1974). Energy functions for peptides and proteins .1. Derivation of a consistent force-field including hydrogen-bond from amide crystals. Journal of the American Chemical Society, 96(17), 5319-5327. Hahn, S. F. (1992). An improved method for the diimide hydrogenation of butadiene and isoprene containing polymers. Journal of Polymer Science Part A: Polymer Chemistry, 30(3), 397-408. Synthesis, analysis, and properties of new crosslinked cellulose plastic films. Journal of Polymer Science Part A: Polymer Chemistry, 43(2), 407-418. compounds. Polymer, 36(26), 5019-5025.

Kar, N., Liu, H., \& Edgar, K. J. (2011). Synthesis of Cellulose Adipate Derivatives. Biomacromolecules, 110323103901076.

Lifson, S., Hagler, A. T., \& Dauber, P. (1979). Consistent force-field studies of inter-molecular forces in hydrogen-bonded crystals .1. Carboxylic-acids, amides, and the $\mathrm{C}=\mathrm{O}$...H hydrogenbonds. Journal of the American Chemical Society, 101(18), 5111-5121.

Lin, Y., Zhang, K. Y., Dong, Z. M., Dong, L. S., \& Li, Y. S. (2007). Study of hydrogen-bonded blend of polylactide with biodegradable hyperbranched poly(ester amide). Macromolecules, 40(17), 6257-6267.

Malzahn, K., Marsico, F., Koynov, K., Landfester, K., Weiss, C. K., \& Wurm, F. R. (2014). Selective interfacial olefin cross metathesis for the preparation of hollow nanocapsules. ACS Macro Letters, 3(1), 40-43.

Meng, X., Matson, J. B., \& Edgar, K. J. (2014a). Olefin cross-metathesis as a source of polysaccharide derivatives: cellulose omega-carboxyalkanoates. Biomacromolecules, 15(1), 177187.

Meng, X., Matson, J. B., \& Edgar, K. J. (2014b). Olefin cross-metathesis, a mild, modular approach to functionalized cellulose esters. Polymer Chemistry, 5(24), 7021-7033.

Ruiz Matute, A. I., Cardelle-Cobas, A., García-Bermejo, A. B., Montilla, A., Olano, A., \& Corzo, N. (2013). Synthesis, characterization and functional properties of galactosylated derivatives of chitosan through amide formation. Food Hydrocolloids, 33(2), 245-255.

Schulz, M. D., \& Wagener, K. B. (2012). Solvent effects in alternating ADMET polymerization. ACS Macro Letters, 1(4), 449-451.

Streuff, J., \& Muñiz, K. (2005). Efficient synthesis of fumaric amides through cross-metathesis of acrylic amides with the NHC Grubbs ruthenium catalyst. Journal of Organometallic Chemistry, 690(24-25), 5973-5978.

Taylor, L. S., \& Zografi, G. (1997). Spectroscopic characterization of interactions between PVP and indomethacin in amorphous molecular dispersions. Pharmaceutical Research, 14(12), 16911698 . 
518 Yu, C., \& Mosbach, K. (1997). Molecular imprinting utilizing an amide functional group for 519 hydrogen bonding leading to highly efficient polymers. Journal of Organic Chemistry, 62(12), 520 4057-4064.

521 Zabivalova, N. M., Bochek, A. M., Kalyuzhnaya, L. M., Vlasova, E. N., \& Volchek, B. Z. 522 (2003). Carboxymethyl cellulose amides and their properties. Russian Journal of Applied 523 Chemistry, 76(12), 1998-2002. 